\title{
Mathematical model of the non-steady-state adsorption and biodegradation capacities of BAC filters
}

\author{
Chung-Huei Liang, Pen-Chi Chiang* \\ Graduate Institute of Environmental Engineering, National Taiwan University, No. 71, Chou-Shan Road, Taipei 106, Taiwan \\ Received 24 January 2006; received in revised form 12 June 2006; accepted 12 June 2006 \\ Available online 16 June 2006
}

\begin{abstract}
This research was focused on developing a non-steady-state numerical model to differentiate the adsorption and biodegradation quantities of a biological activated carbon (BAC) column. The mechanisms considered in this model included adsorption, biodegradation, convection and diffusion. Simulations were performed to evaluate the effects of some parameters such as specific biodegradation rates and diffusivities on adsorption and biodegradation performances for the removal of dissolved organic matter from water. The results show that the developed model can predict the experimental data well.

The biofilm developed around the BAC granules can hinder the mass transfer of the substrate onto the GAC surface, and the adsorption process will be restricted by the biofilm thickness. Although increasing the specific biodegradation rate can increase the performance of biodegradation, the adsorption efficiency will be decreased by lowering the boundary concentration in the interface of GAC. On the contrary, increasing the diffusivity can increase both the adsorption and biodegradation efficiencies simultaneously; so that the overall removal efficiency can be promoted through the improvement of mass transfer.
\end{abstract}

(C) 2006 Elsevier B.V. All rights reserved.

Keywords: Adsorption; Biodegradation; Biological activated carbon (BAC); Granular activated carbon (GAC); Numerical model

\section{Introduction}

In water treatment processes, using biological activated carbon (BAC), which includes both adsorption and biodegradation mechanisms, to reduce ozonation by-products (OBPs) has the advantages of lowing the regeneration cost and prolonging the life of granular activated carbon (GAC) beds [1,2]. Besides the removals of the typical OBPs, the BAC process is also capable of removing other contaminants, such as non-ionogenic synthetic surfactants [3], ammonia [4], and bromate as bromide in source waters reacting with ozone [5]. In our previous study, adsorption is the prevailing mechanism for the removal of $p$ hydroxybenzoic acid, and biodegradation is responsible for the removal of ozonation intermediates [6].

The adsorption and biodegradation mechanisms overlap in the $\mathrm{BAC}$ bed, and it is difficult to recognize the predominant

\footnotetext{
* Corresponding author at: Graduate Institute of Environmental Engineering, National Taiwan University, Room 312, No. 130, Section 3, Keelung Road, Taipei 106, Taiwan. Tel.: +88622362 3433; fax: +886223661642.

E-mail address: d86541002@ntu.edu.tw (P.-C. Chiang).
}

mechanism in removing contaminants. In the review of the literature regarding biofilter models [7], limited information was mentioned about the removal mechanism. Most researches for the development of biofilter models were focused on the evolution of biodegradation [8-16], and some of the representative models are listed in Table 1. Chang and Rittmann [10] developed a mathematical model of biofilm on activated carbon, which could quantify the extent of adsorption and biodegradation. The most important contribution was to elucidate the substrate passing through the biofilm and then absorbed by the GAC; that is, the flux from biofilm is identical to the substrate absorbed on a GAC granule. However, it could not be applied under unsteady or plug-flow conditions. In an experimental study on column breakthrough, the capacities of GAC and BAC columns were derived, but the interaction between the two mechanisms still remains unclear [17]. Sakoda et al. [12] suggested a theoretical model in 1996 for a BAC column. The transport mechanisms in the column included dispersion, convection, biodegradation and adsorption, and the basic simplifying assumption was that the substrate concentration in the interface between the biofilm and the GAC was identical to that in the bulk solution. In 1997, 
Table 1

Some of the representative BAC models

\begin{tabular}{|c|c|c|c|c|c|c|c|c|}
\hline \multirow[t]{2}{*}{ Reactor type } & \multirow{2}{*}{$\begin{array}{l}\text { Terms in governing } \\
\text { equation }^{\mathrm{a}}\end{array}$} & \multicolumn{4}{|c|}{ Kinetic condition } & \multirow{2}{*}{$\begin{array}{l}\text { Mass transport } \\
\text { description }^{b}\end{array}$} & \multirow{2}{*}{$\begin{array}{l}\text { Solution } \\
\text { method }\end{array}$} & \multirow[t]{2}{*}{ Authors } \\
\hline & & $\begin{array}{l}\text { Substrate in } \\
\text { bulk phase }\end{array}$ & $\begin{array}{l}\text { Substrate } \\
\text { in biofilm }\end{array}$ & $\begin{array}{l}\text { Biofilm } \\
\text { amount }\end{array}$ & Substrate in GAC & & & \\
\hline $\begin{array}{r}\text { Complex } \\
\text { mixing }\end{array}$ & A, B & Non-steady & Monod & Non-steady & Non-equilibrium & $1,2,3,4,5$ & Analytical & Chang and Rittmann, [10] \\
\hline Column & $\mathrm{A}, \mathrm{B}, \mathrm{C}, \mathrm{D}$ & Non-steady & n.a. ${ }^{\mathrm{c}}$ & Steady & Equilibrium & 1 & Analytical & Sakoda et al. [12] \\
\hline Column & $\mathrm{A}, \mathrm{B}$ & Uniform & Monod & Non-steady & n.a. ${ }^{\mathrm{c}}$ & 1 & Analytical & Walker and Weatherley [14] \\
\hline Column & $\mathrm{A}, \mathrm{B}, \mathrm{C}$ & Non-steady & Monod & Steady & Non-equilibrium & 1,5 & Analytical & Abumaizar et al. [15] \\
\hline Column & $\mathrm{B}, \mathrm{C}, \mathrm{D}$ & Non-steady & Monod & Non-steady & n.a. ${ }^{\mathrm{c}}$ & $1,2,3$ & Numerical & Hozalski and Bourer [16] \\
\hline
\end{tabular}

${ }^{a}$ A: adsorption, B: biodegradation, C: convection, D: dispersion.

b 1: bulk phase, 2: interface between bulk phase and biofilm, 3: biofilm, 4: interface between biofilm and GAC, 5: GAC.

c Not analyzed in the article.

Walker and Weatherley [14] proposed a simplified predictive model for biologically activated carbon fixed beds based on Monod kinetics. Their mathematical development was based on the assumptions that the BAC system was a simple combination of adsorption and biodegradation, so that the detailed analysis of simultaneous diffusion and biodegradation in the biofilm was not needed. A detailed biofilter model was reported by Hozalski and Bourer [16]. In their model the length of the biofilm was dynamic and controlled by biotic parameters as well as mass transport.

This research developed a numerical model to simulate both adsorption and biodegradation quantities of a BAC column under a non-steady-state condition, so as to predict the effluent concentration, biomass profiles, and the residual capacity of adsorption. The basic assumptions of the models are: (1) the granules used in BAC are sphere in shape; (2) biodegradation reaction can be neglected in the pores of the granules, because the size of most meso or micro pores $(<0.05 \mu \mathrm{m})$ of GAC are less than the size of a microbe, so cannot permit bacteria to penetrate; furthermore, desorption after the saturation of the GAC was not taken into considered because this model was focus on the simulation of a virgin GAC; (3) the biofilm is homogeneous and the density of the biofilm is constant; (4) mass transfer phenomenon is dominated by Fick's law; (5) transport of substrate through the column is by dispersion and advection; (6) transport of substrate within the biofilm is by diffusion; (7) substrate is utilized by both immobilized and suspended bacteria. In addition, a series of bench-scale continuous column tests were performed for the purpose of model calibration and validation, and for the assessment of the effect of empty bed contact time (EBCT) on the removal of OBPs.

\section{Materials and methods}

\subsection{Model development}

The conceptual diagram of a granule is shown in Fig. 1, and the governing equation based on mass balance for the substrate concentration in the liquid phase of the BAC column is:

$$
\begin{aligned}
\varepsilon \frac{\partial S_{\mathrm{b}}}{\partial t}= & D_{\mathrm{b}} \frac{\partial^{2} S_{\mathrm{b}}}{\partial x^{2}}-v \frac{\partial S_{\mathrm{b}}}{\partial x}-\frac{1-\varepsilon}{V_{\mathrm{g}}} \\
& \times \int_{0}^{L_{\mathrm{f}}} \frac{k_{\mathrm{f}} X_{\mathrm{f}} S_{\mathrm{f}}}{K_{\mathrm{f}}+S_{\mathrm{f}}} 4 \pi\left(r_{\mathrm{f}}+R_{\mathrm{g}}\right)^{2} \mathrm{~d} r_{\mathrm{f}} \\
& -(1-\varepsilon) \rho_{\mathrm{g}} \frac{\partial q_{\mathrm{a}}}{\partial t}-\varepsilon\left(\frac{k_{\mathrm{b}} X_{\mathrm{b}} S_{\mathrm{b}}}{K_{\mathrm{b}}+S_{\mathrm{b}}}\right)
\end{aligned}
$$

where $\varepsilon$ is the bed porosity of the BAC column; $S_{\mathrm{b}}$ the substrate concentration in the liquid phase $\left(\mathrm{M} / \mathrm{L}^{3}\right) ; D_{\mathrm{b}}$ the dispersion coefficient in the liquid phase $\left(\mathrm{L}^{2} / \mathrm{T}\right) ; x$ the distance along the BAC column (L); $v$ the superficial velocity (L/T); $V_{\mathrm{g}}$ the volume of a GAC granule $\left(\mathrm{L}^{3}\right) ; L_{\mathrm{f}}$ the length of the biofilm $(\mathrm{L}) ; k_{\mathrm{f}}$ the maximum utilization rate in the biofilm (M/T-cell); $X_{\mathrm{f}}$ the cell density of the biofilm (cell/ $\left./ \mathrm{L}^{3}\right) ; S_{\mathrm{f}}$ the substrate concentration in the biofilm $\left(\mathrm{M} / \mathrm{L}^{3}\right) ; K_{\mathrm{f}}$ the Monod half-velocity coefficient in the biofilm $\left(\mathrm{M} / \mathrm{L}^{3}\right) ; r_{\mathrm{f}}$ and $R_{\mathrm{g}}$ the radius of the biofilm and the GAC

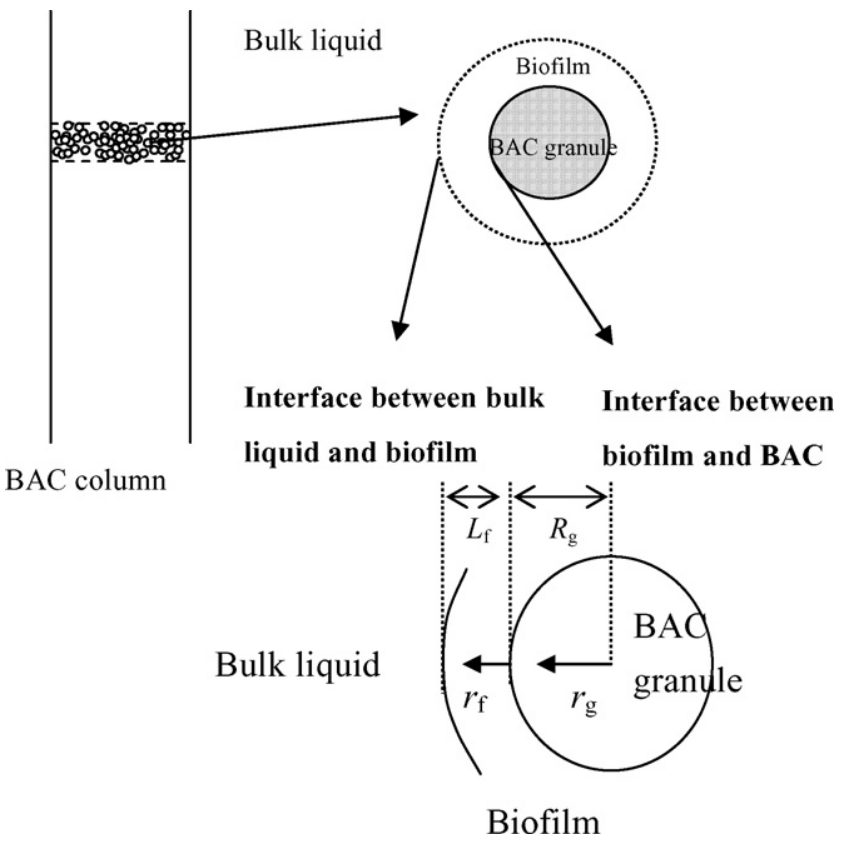

Fig. 1. Conceptual basis of biological activated carbon coordinate system. 
granule, respectively (L); $\rho_{g}$ the GAC granule apparent density $\left(\mathrm{M} / \mathrm{L}^{3}\right) ; q_{\mathrm{a}}$ the adsorption capacity $(\mathrm{M} / \mathrm{M}) ; k_{\mathrm{b}}$ the maximum utilization rate in the liquid phase (M/T-cell); $X_{\mathrm{b}}$ the cell density in the liquid phase (cell/ $\left./ \mathrm{L}^{3}\right) ; K_{\mathrm{b}}$ is the Monod half-velocity coefficient in the liquid phase $\left(\mathrm{M} / \mathrm{L}^{3}\right)$.

The boundary conditions (BC) of the dispersion-advectionreaction equation are shown below:

$\mathrm{BC} 1: \quad S_{\mathrm{b}}=S_{\mathrm{b} 0}, \quad x=0, t \geq 0$

BC 2 : $\quad \frac{\partial S_{\mathrm{b}}}{\partial x}=\left.0\right|_{x=L_{\mathrm{c}}}$

where $L_{\mathrm{c}}$ is the length of the BAC column (L).

The non-steady-state form of mass transfer and biodegradation reaction within biofilm, based on Fick's law and Monod equation, can be expressed as:

$\frac{\partial S_{\mathrm{f}}}{\partial t}=D_{\mathrm{f}} \frac{\partial^{2} S_{\mathrm{f}}}{\partial r_{\mathrm{f}}^{2}}-\frac{k_{\mathrm{f}} S_{\mathrm{f}}}{K_{\mathrm{s}}+S_{\mathrm{f}}} X_{\mathrm{f}}, \quad 0 \leq r_{\mathrm{f}} \leq L_{\mathrm{f}}$

where $D_{\mathrm{f}}$ is the diffusivity within the biofilm $\left(\mathrm{L}^{2} / \mathrm{T}\right)$. Eq. (4) describes a non-steady-state biofilm condition where diffusion and reaction are simultaneously occurred.

One BC for Eq. (4) is that a diffusion layer exists between the bulk solution and the biofilm, and the BC can be simplified as:

$\left.S_{\mathrm{f}}\right|_{r_{\mathrm{f}}=0}=k_{\mathrm{bf}} S_{\mathrm{b}}$

where $k_{\mathrm{bf}}$ is a factor to estimate the concentration reduction within the diffusion layer.

Another BC for Eq. (4) is the interface between the biofilm and the GAC surface which is based on the equilibrium of the substrate. In the study conducted by Chang and Rittmanns [10], they assumed that there existed an interface between the activated carbon and the biofilm, and used a Fruendlich isotherm to describe the equilibrium at the interface. In this study, the Langmuir isotherm was used for the calculation of the boundary concentration of the biofilm near the GAC side, which was derived from the solid phase concentration of the adsorbates. For single-component adsorbate:

$q_{\mathrm{s}}=\frac{q_{0} K_{\mathrm{L}} C_{\mathrm{a}}}{1+K_{\mathrm{L}} C_{\mathrm{a}}}$

where $q_{\mathrm{s}}$ is the surface concentration $(\mathrm{M} / \mathrm{M}) ; q_{0}$ the unitlayer adsorption capacity $(\mathrm{M} / \mathrm{M}) ; K_{\mathrm{L}}$ the Langmuir coefficient $\left(\mathrm{L}^{3} / \mathrm{M}\right) ; C_{\mathrm{a}}$ is the concentration on the boundary of the biofilm $\left(\mathrm{M} / \mathrm{L}^{3}\right)$.

The calculation for the adsorption capacity is based on the fact that the flux from biofilm is identical to the substrate absorbed on a GAC granule:

$\left.4 \pi r_{\mathrm{g}}^{2} D_{\mathrm{f}} \frac{\partial S_{\mathrm{f}}}{\partial r_{\mathrm{f}}}\right|_{r_{\mathrm{f}}=L_{\mathrm{f}}}=\frac{\partial q_{\mathrm{a}}}{\partial t} m_{\mathrm{g}}$

where $m_{\mathrm{g}}$ is the mass of a GAC granule (M).

Substrate diffusing into biofilm will be utilized by bacteria for metabolism. In this research, biodegradation reaction can be neglected in the pores of the granules, because the sizes of pores are too small for most bacteria to penetrate. In a control volume, the average biodegradation rate can be derived by integrating the Monod reaction expression and the amount of biofilm volume:

$\left[\int_{0}^{L_{\mathrm{f}}} \frac{k_{\mathrm{f}} S_{\mathrm{f}}}{K_{\mathrm{S}}+S_{\mathrm{f}}} X_{\mathrm{f}} 4 \pi\left(r_{\mathrm{g}}+r_{\mathrm{f}}\right)^{2} \mathrm{~d} r_{\mathrm{f}}\right] N_{\mathrm{g}}, \quad 0 \leq r_{\mathrm{f}} \leq L_{\mathrm{f}}$

$N_{\mathrm{g}}=\frac{\Delta V(1-\varepsilon)}{V_{\mathrm{g}}}$

where $\Delta V$ is a control volume unit of the BAC bed $\left(\mathrm{L}^{3}\right) ; N_{\mathrm{g}}$ is the number of BAC granules in a control volume.

On the other hand, the thickness of biofilm will increase due to growth, and decrease by the shear of water, and the self decay of bacteria. In an arbitrary location of the column, the biofilm thickness can be described as an initial value problem:

$$
\begin{gathered}
\frac{\mathrm{d} L_{\mathrm{f}}}{\mathrm{d} t}=\frac{Y \int_{0}^{L_{\mathrm{f}}} \frac{k_{\mathrm{f}} S_{\mathrm{f}}}{K_{\mathrm{s}}+S_{\mathrm{f}}} X_{\mathrm{f}} 4 \pi\left(r_{\mathrm{g}}+r_{\mathrm{f}}\right)^{2} \mathrm{~d} r_{\mathrm{f}}}{A_{\mathrm{f}} X_{\mathrm{f}}}-b_{\text {tot }} L_{\mathrm{f}}, \\
0 \leq r_{\mathrm{f}} \leq L_{\mathrm{f}}
\end{gathered}
$$

where $Y$ is the yield coefficient of biomass (CFU/M); $A_{\mathrm{f}}$ is the surface area of a BAC granule $\left(\mathrm{L}^{2}\right)$.

The parameter $b_{\text {tot }}$ is the overall loss rate of bacteria due to both endogenous decay and detachment. The detachment of biofilm includes two mechanisms, sloughing and erosion. Under steady-state the biofilm is dynamic-equivalent; that is, the detachment rate is equal to the growth rate. However, it should be noted that this equivalence may be the result of local stochastic fluctuations of the biofilm [18]. Many conditions can affect the detachment behavior of biofilm. Telgmann et al. [19] summarized the difficulties for describing the detachment of biofilm by average parameters, including thickness and density, growth rate, and shear force, but there still existed a weak relationship between the amount of detached biomass and the average biofilm thickness before detachment [20]. Moreover, the biofilm microstructure can result in different flow patterns and boundary layers, so as to cause different shear stress on the attached biofilm [21]. In this model study two mechanisms, i.e. endogenous decay and detachment were considered, for the calculation of the loss of biofilm, and the values were cited from the literature [22].

The factors affecting bacterial density in the bulk solution include the mass transfer rates of dispersion and advection, growth and decay of bacteria, peeled bacteria from biofilm due to shear force, and the interception loss by the granule. However, the dispersion term, and the affects of growth and decay are insignificant in a macro scope [16]. In this research, the governing equation for the bacterial density in bulk solution can be simplified as an advection-reaction form:

$$
\frac{\partial X_{\mathrm{b}}}{\partial t}=-v \frac{\partial X_{\mathrm{s}}}{\partial x}+\frac{Y k_{\mathrm{b}} S_{\mathrm{b}} X_{\mathrm{b}}}{K_{\mathrm{b}}+S_{\mathrm{b}}}
$$

The boundary conditions of Eq. (11) are shown below:

$$
\begin{array}{ll}
\mathrm{BC} 1: & X_{\mathrm{b}}=X_{0}, \quad x=0, \quad t \geq 0 \\
\mathrm{BC} 2: & \frac{\partial X_{\mathrm{b}}}{\partial x}=\left.0\right|_{x=L_{\mathrm{c}}}
\end{array}
$$


Table 2

Operation conditions and parameters used for model simulation

\begin{tabular}{|c|c|c|c|}
\hline Parameter (symbol) & Value & Unit & Source \\
\hline \multicolumn{4}{|l|}{ BAC filter and operation specifications } \\
\hline Column length $\left(L_{\mathrm{c}}\right)$ & 50 & $\mathrm{~cm}$ & \multirow{8}{*}[23]{} \\
\hline Column diameter $\left(d_{\mathrm{c}}\right)$ & 5 & $\mathrm{~cm}$ & \\
\hline Porosity $(\varepsilon)$ & 0.4 & - & \\
\hline Superficial velocity $(v)$ & 1200 & $\mathrm{~cm} / \mathrm{h}$ & \\
\hline GAC granule radius $\left(R_{\mathrm{g}}\right)$ & 0.15 & $\mathrm{~cm}$ & \\
\hline GAC granule apparent density $\left(\rho_{\mathrm{g}}\right)$ & 0.88 & $\mathrm{~g} / \mathrm{cm}^{3}$ & \\
\hline Initial biofilm thickness & 0.2 & $\mu \mathrm{m}$ & \\
\hline Temperature & 25 & ${ }^{\circ} \mathrm{C}$ & \\
\hline \multicolumn{4}{|l|}{ Substrate properties } \\
\hline Influent concentration $\left(S_{\mathrm{b} 0}\right)$ & 0.4 & $\mathrm{mg} \mathrm{DOC/L}$ & {$[23]$} \\
\hline Dispersion coefficient $\left(D_{\mathrm{b}}\right)$ & 1620 & $\mathrm{~cm}^{2} / \mathrm{h}$ & \multirow{2}{*}{ Calculated $^{\mathrm{a}}$} \\
\hline Diffusivity in biofilm $\left(D_{\mathrm{f}}\right)$ & $2.9 \times 10^{-2}$ & $\mathrm{~cm}^{2} / \mathrm{h}$ & \\
\hline \multicolumn{4}{|l|}{ Biokinetic and bioassay constants } \\
\hline Maximum specific substrate utilization rate in water, biofilm $\left(k_{\mathrm{b}}, k_{\mathrm{f}}\right)$ & $1.7 \times 10^{-10}$ & $\mathrm{mg}$ DOC/CFU h & \multirow{4}{*}[16]{} \\
\hline Half-velocity concentration in water, biofilm $\left(K_{\mathrm{b}}, K_{\mathrm{f}}\right)$ & 0.1 & $\mathrm{mg} \mathrm{DOC} / \mathrm{L}$ & \\
\hline Snecific vield $(Y)$ & $6.45 \times 10^{8}$ & $\mathrm{CFU} / \mathrm{mg}$ & \\
\hline Specific yield $(Y)$ & 0.33 & cell/substrate & \\
\hline Biofilm density $\left(X_{\mathrm{f}}\right)$ & $5.0 \times 10^{13}$ & $\mathrm{CFU} / \mathrm{L}$ & \\
\hline Total decay coefficient $\left(b_{\text {tot }}\right)$ & 0.25 & day $^{-1}$ & {$[22]$} \\
\hline \multicolumn{4}{|l|}{ Adsorption constants } \\
\hline Langmuir unit-layer adsorption capacity $\left(q_{0}\right)$ & 0.3 & $\mathrm{~g}$ DOC/g GAC & \multirow{2}{*}[23]{} \\
\hline Langmuir coefficient $\left(K_{\mathrm{L}}\right)$ & 18 & $\mathrm{~L} / \mathrm{mg}$ & \\
\hline
\end{tabular}

${ }^{a}$ Wilke and Chang equation in [10].

\subsection{Numerical solution}

The governing equation of the substrate concentration in bulk solution is a second-order partial differential equation, and can be approximated by the Crank-Nicolson finite difference method, with the Crout factorization method for solving tridiagonal linear system. The initial condition is:

$S_{\mathrm{b}}(x, t)=0, \quad t=0$

$q_{\mathrm{a}}(t)=0, \quad t=0$

The non-steady-state substrate concentration within the biofilm was also approximated by the Crank-Nicolson finite difference method, and the initial condition is:

$S_{\mathrm{f}}\left(r_{\mathrm{f}}, t\right)=0, \quad t=0$

The program was written in FORTRAN 90 developed by the Microsoft PowerStation. The parameters used for simulation are listed in Table 2.

\subsection{Lab-scale column system}

The effective length of each experimental column was $50 \mathrm{~cm}$ with EBCTs controlled at 2.5 and $10 \mathrm{~min}$. The GAC was washed in de-ionized water (Milli-Q SP) and then dried at $250{ }^{\circ} \mathrm{C}$ for $24 \mathrm{~h}$, and then packed with a dry weight of $304 \mathrm{~g}$. The feed solution consisted of four OBPs, including two aldehydes (formaldehyde and glyoxal, Sigma) and two ketoacids (glyoxalic and ketomalonic acid, Sigma); the total dissolved organic carbon (DOC) was $0.4 \mathrm{mg} / \mathrm{L}$. The detailed experimental procedure and results were described in our previous study [23].

\section{Results and discussion}

\subsection{Influences of the biofilm thickness}

The biomass activity represented as biomass respiration potential (BRP) on the GAC granules was shown in Fig. 2, and the sampling location was at the top $(L=0+\mathrm{cm})$ of the column. This method was reported by Ufer and Huck [24] who successfully employed the BRP method to determine the activity of biomass attached to the drinking water biofilter media. On the same time, Fig. 2 also shows the biofilm thickness simulated by this model. In this study, one of the major roles of the biofilm thickness is for the calculation of biodegradation. Generally, the magnitude of bioactivity depends not only on the biomass quantity, but also on the composition of the

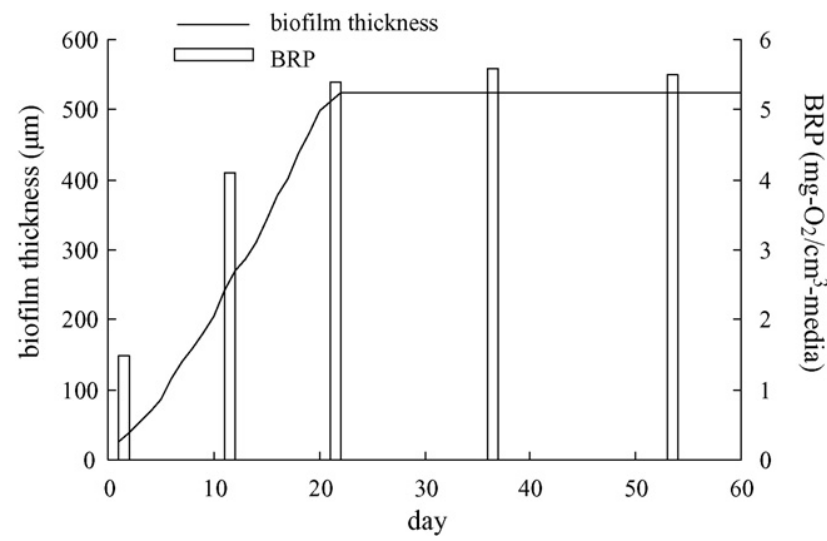

Fig. 2. The biofilm thickness and specific BRP profiles of the BAC column (EBCT $=10 \mathrm{~min}$, sampled on the top of the column). 


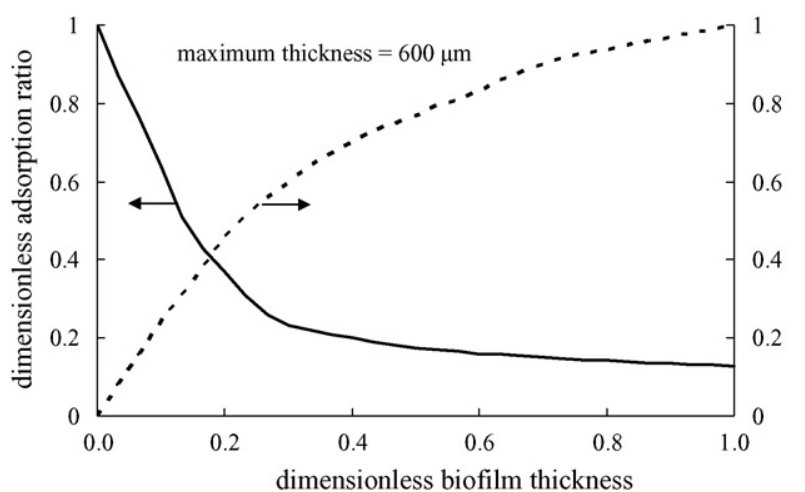

Fig. 3. Biodegradation and adsorption rates as functions of the biofilm thickness.

microbe itself. Despite the heterogeneity, our model used an integrated value for the calculation of biodegradation, and the result of the simulated biofilm thickness shows a similar trend to the BRP.

Another key influence of the biofilm thickness is to determine the mass transfer rate outside GAC granules for adsorption. The influences of biofilm thickness on adsorption and biodegradation are shown in Fig. 3. The dimensionless adsorption ratio is the adsorption rate (as a function of the biofilm thickness) divided by the maximum adsorption rate $\left(L_{\mathrm{f}}=0\right)$; and the dimensionless biodegradation ratio is the biodegradation rate divided by the maximum biodegradation rate occurring when the biofilm thickness is maximum (here $600 \mu \mathrm{m}$ was assumed). The other input parameters are the same in Table 2. For biodegradation, at half of the maximum thickness, the dimensionless biodegradation rate was 0.8 . This result indicated that the quantity of biodegradation was not linearly proportional to the biofilm thickness. On the other hand, the dimensionless adsorption rate dramatically decreased as the biofilm thickness increased. It was found that at 0.4 maximum thickness, the adsorption rate decreased from 1.0 to $\sim 0.2$. This result showed that the inter-particle mass transfer for adsorption was hindered by the biofilm. Moreover, as the substrate passing through the biofilm, the driving force for adsorption was lowered as the consequence of biomass uptake.

\subsection{Model calibration and validation-the effluent concentration}

During the calculation process of simulation, the liquid-film mass transfer coefficient $\left(k_{\mathrm{bf}}\right)$ played an important role as a correcting factor. In our previous study [23], glass beads were used as packing media, the model can be simplified as only biodegradation and the best $k_{\mathrm{bf}}$ value for simulation could be acquired by adjusting the simulation curve to the experimental data. The results can be represented quantitatively by the least square value ( $N$ is the number of data points):

Average least square value $=\frac{1}{N} \sum_{\text {all data points }} \sqrt{\frac{\left(C_{\mathrm{eff}}^{\mathrm{sim}}-C_{\mathrm{eff}}^{\mathrm{exp}}\right)^{2}}{\left(C_{\mathrm{eff}}^{\text {exp }}\right)^{2}}}$
Table 3

The average fit value for $k_{\mathrm{bf}}$ value in the glass bead case

\begin{tabular}{lllll}
\hline $\mathrm{EBCT}=2.5 \mathrm{~min}$ & & & $\mathrm{EBCT}=10 \mathrm{~min}$ \\
\cline { 1 - 2 }$k_{\mathrm{bf}}$ value & $\begin{array}{l}\text { Average least } \\
\text { square value }\end{array}$ & & $k_{\mathrm{bf}}$ value & $\begin{array}{l}\text { Average least } \\
\text { square value }\end{array}$ \\
\hline 0.2 & 0.20 & 0.2 & 0.33 \\
0.3 & 0.16 & 0.3 & 0.26 \\
0.4 & 0.14 & 0.4 & 0.18 \\
0.5 & 0.13 & 0.5 & 0.14 \\
0.6 & 0.14 & 0.6 & 0.13 \\
0.7 & 0.18 & 0.7 & 0.15 \\
0.8 & 0.25 & 0.8 & 0.27 \\
\hline
\end{tabular}

The average least square value provides a quantitative comparison of the agreement between a simulation and experimental data. As the average least square value increases, the level of agreement between the two simulations decreases. According to the results of the glass bead column, shown in Table 3, the $k_{\mathrm{bf}}$ value are chosen within a range of $0.5-0.6$, and then the model can get a good approximation to the experimental data for the glass bead column. It should be noted that a higher $k_{\mathrm{bf}}$ permits a higher driving force on the biofilm boundary, and makes substrate concentration profile higher within the biofilm; as a consequence, the amounts of biodegradation and adsorption can be increased.

The simulation effluent curves of the substrate concentration of the BAC column under EBCT $=2.5$ and $10 \mathrm{~min}$ are shown in Fig. 4. The removal efficiencies of the two EBCT cases at a steady-state show a trend that the removal efficiencies increased as the EBCT increased. However, the increment was insignificant in comparison with the increase of the EBCT. It should also be noted that the $k_{\mathrm{bf}}$ value is a little higher for EBCT $=10 \mathrm{~min}$ than that for $\mathrm{EBCT}=2.5 \mathrm{~min}$. This phenomenon suggests that extending EBCT can derive a stronger driving force for the mass transfer within the biofilm. From the simulation and experimental results, it was concluded that the BAC column could not effectively remove the substrate until biodegradation reached equilibrium. In this research, biodegradation changed from an unsteady

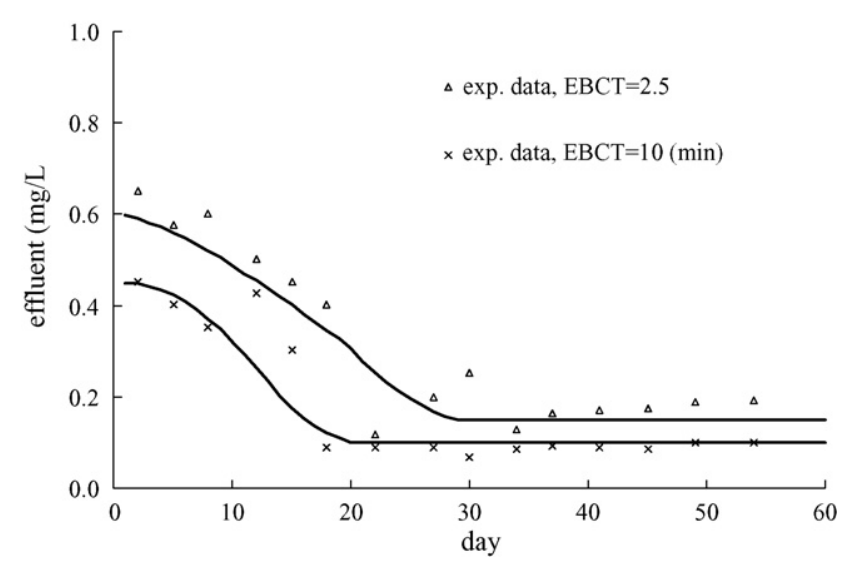

Fig. 4. Simulation effluent curves and the experimental data of the substrate concentration of the BAC column. 


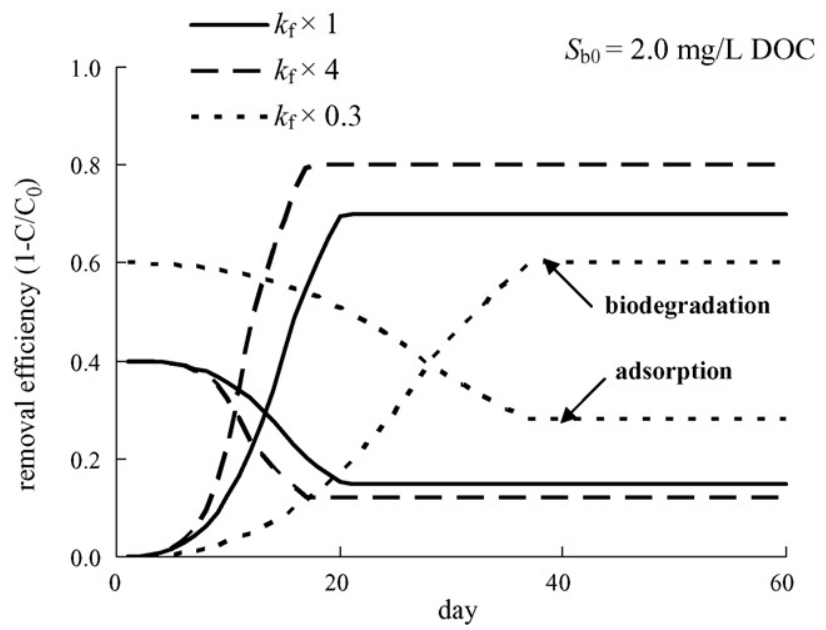

Fig. 5. Simulation removal efficiencies of adsorption and biodegradation under various specific substrate utilization rates in the biofilm $\left(k_{\mathrm{f}}\right)$.

to a steady-state after approximately $2-3$ weeks of operation when the effluent concentrations varied within a narrow range.

\subsection{Effects of adsorption/biodegradation ratios on the performance of DOC removal}

To determine the effects of adsorption/biodegradation ratio on the removal efficiencies of the BAC column, a simulation procedure was computed to calculate the amount of DOC adsorbed and biodegraded in the BAC column. For changing the properties of the target compound, the maximum specific substrate utilization rate in the biofilm $\left(k_{\mathrm{f}}\right)$ was multiplied by 4 and 0.3 for simulation. The input parameters except influent DOC $(2.0 \mathrm{mg} / \mathrm{L})$ and $k_{\mathrm{f}}$ were the same of Table 2 in all simulation cases, and the results are shown in Fig. 5. It was expected that decreasing $k_{\mathrm{f}}$ can decrease the biodegradation quantity (dotted line), as a result the adsorption efficiency increased at the same time. A reasonable explanation is that less substrate was biodegraded, which increased the boundary concentration in the interface of GAC. On the other hand, increasing $k_{\mathrm{f}}$ increased the amount of substrate biodegraded (broken line), but the adsorption efficiency was decreased at the same time. This is likely because more substrate was biodegraded and the equilibrium concentration for adsorption was lower.

According to the simulation above, the simulated effluent and the ratio of biodegradation to total removal efficiency are shown in Fig. 6. It is clear that increasing $k_{\mathrm{f}}$ could improve the overall removal efficiency, even though the adsorption slightly decreased; and, in this case, biodegradation was the dominated mechanism for the organic matter removal (about 88\%) after biodegradation equilibrium. However, as the biofilm grew thicker, the adsorption process was hindered thereafter, and the overall performance became worse until biodegradation reaching an equilibrium state. By that time, biodegradation was the dominated mechanism for the organic matter removal (about $68 \%)$. Moreover, the results reflect the role of adsorption at the beginning, and the importance of biodegradation after bioequilibrium for the performance of a BAC column.

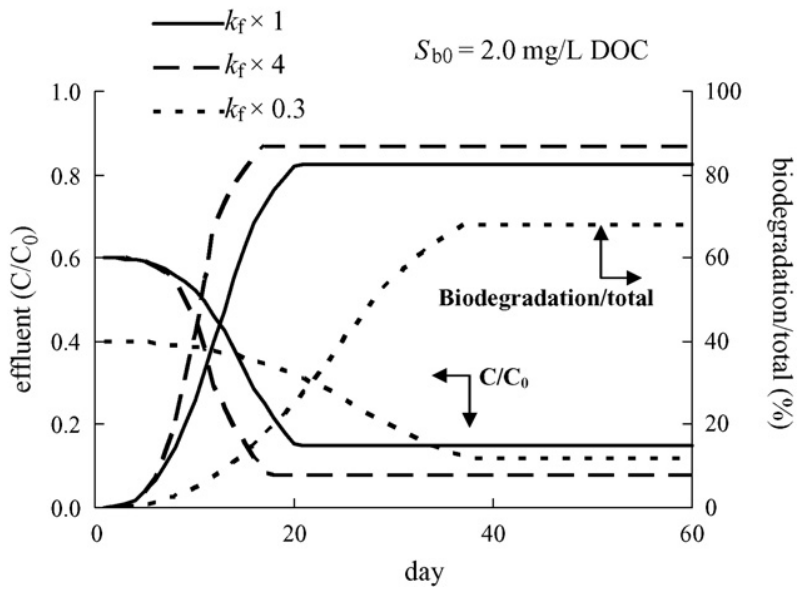

Fig. 6. Simulation effluents and the ratio of biodegradation to total removal efficiency under various specific substrate utilization rates in the biofilm $\left(k_{\mathrm{f}}\right)$.

\subsection{Effects of diffusivity on adsorption/biodegradation for the BAC column}

As mentioned previously, the mass transfer within in biofilm was the key factor for the performance of BAC, especially for the adsorption process. The substrate mass flux from bulk liquid transferring to the surface of GAC granules was controlled by the thickness of the biofilm, the diffusivity within the biofilm $\left(D_{\mathrm{f}}\right)$, and the uptake of microbes. Moreover, $D_{\mathrm{f}}$ can also influence the concentration profile within the biofilm, so as to change the magnitude of the amount of biodegradation.

To determine effects of $D_{\mathrm{f}}$ value on the removal efficiencies of the BAC column, a simulation procedure was developed to calculate the amount of DOC adsorbed and biodegraded in the BAC column. For changing the magnitude of the $D_{\mathrm{f}}$, the diffusivity was multiplied by $0.2-10$. The influent DOC were $2.0 \mathrm{mg} / \mathrm{L}$ in all simulation cases, and the results are shown in Fig. 7. It was expected that increasing $D_{\mathrm{f}}\left(D_{\mathrm{f}} \times 10\right.$, broken line) can improve the mass transfer process. On the contrary, decreasing $D_{\mathrm{f}}$ can decrease both the adsorption and biodegradation efficiencies $\left(D_{\mathrm{f}} \times 0.2\right.$, dotted line). The effect of changing

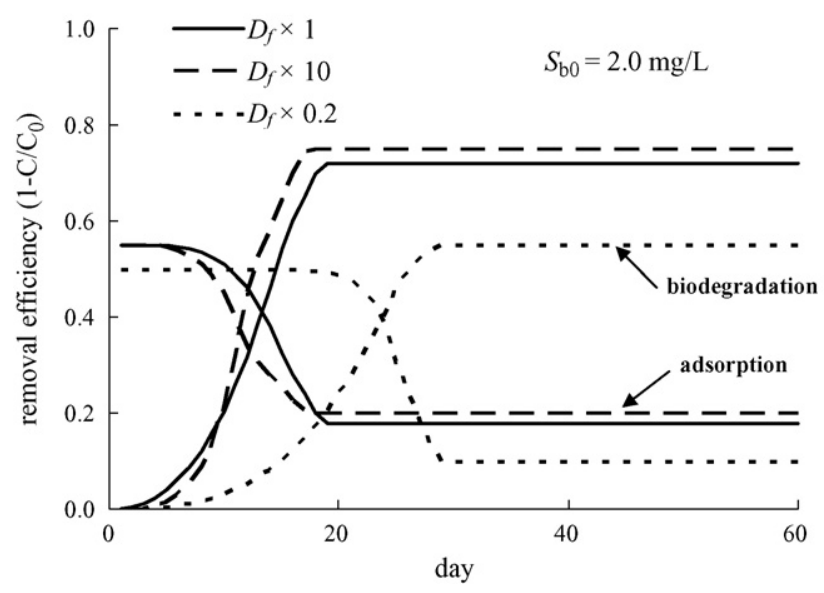

Fig. 7. Simulation removal efficiencies of adsorption and biodegradation under various diffusivities in the biofilm $\left(D_{\mathrm{f}}\right)$. 


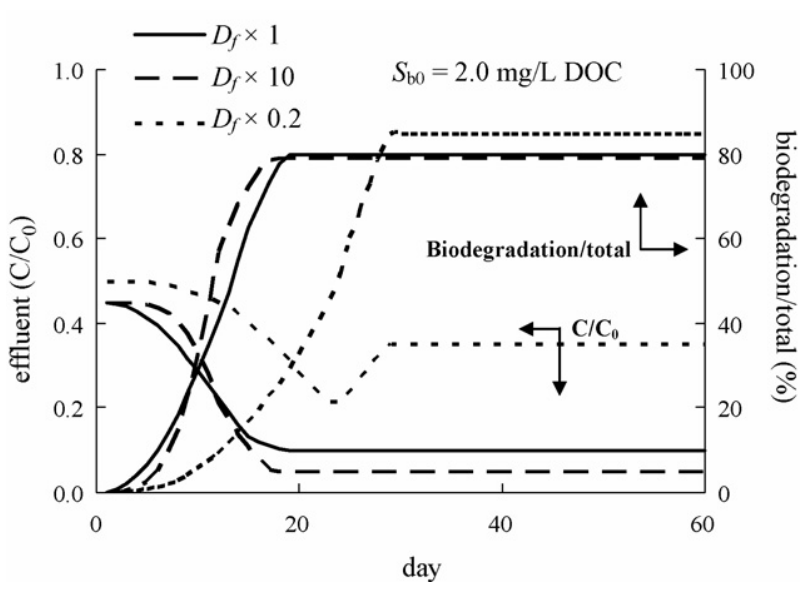

Fig. 8. Simulation effluents and the ratio of biodegradation to total removal efficiency under various diffusivities in the biofilm $\left(D_{\mathrm{f}}\right)$.

diffusivities on adsorption and biodegradation is different from that of changing specific biodegradation rates. Increasing the diffusivity can increase both the adsorption and biodegradation efficiencies simultaneously. However, increasing the substrate utilization rate can only increase biodegradation efficiency, so that the amount of substrate that can be adsorbed decreases under a fixed mass transfer rate.

According to the simulation above, the simulated effluent and the ratio of biodegradation to total removal efficiency are shown in Fig. 8. It is clear that increasing $D_{\mathrm{f}}$ could improve the overall removal efficiency; and, in this case, the biodegradation/total ratio slightly decreased to $77 \%$ after the biodegradation equilibrium was reached. On the other hand, decreasing $D_{\mathrm{f}}$ could reduce the overall removal efficiency, and the biodegradation/total ratio slightly increased to $86 \%$ after the biodegradation equilibrium was reached.

\section{Conclusions}

This model achieves a good approximation of the experimental data under the liquid-film mass transfer coefficients $\left(k_{\mathrm{bf}}\right)$ of 0.5 and 0.6 for $\mathrm{EBCT}=2.5$ and $10 \mathrm{~min}$, respectively. A higher $k_{\text {bf }}$ permits a higher pressure gradient on the biofilm boundary, and results in a higher substrate concentration profile within the biofilm; as a consequence, the amounts of biodegradation and adsorption can be increased.

The biofilm developed around the BAC granules could hinder the mass transfer of the substrate onto the GAC surface, and this implied that the adsorption process would be restricted by the biofilm. Decreasing $k_{\mathrm{f}}$ can decrease the biodegradation quantity, as a result the adsorption efficiency increased at the same time by increasing the boundary concentration in the interface of GAC.

The effect of changing $D_{\mathrm{f}}$ on adsorption and biodegradation is different from that of changing $k_{\mathrm{f}}$. Increasing the diffusivity can increase both the adsorption and biodegradation efficiencies simultaneously. It was concluded that improving the efficiency of mass transfer can improve the overall removal efficiency.

\section{References}

[1] P. Servais, G. Billen, C. Ventresque, G.P. Bablon, Microbial activity in GAC filters in the Choisy-le-Roi treatment plant, J. Am. Water Works Assoc. 83 (1991) 62-68.

[2] M.W. LeChevallier, W.C. Becker, P. Schorr, R.G. Lee, Evaluating the performance of biological active rapid filter, J. Am. Water Works Assoc. 84 (1992) 136-146.

[3] A.S. Sirotkin, L.Y. Koshkina, K.G. Ippolitov, The BAC-process for treatment of waste water containing non-ionogenic synthetic surfactants, Water Res. 35 (2001) 3265-3271.

[4] A. Andersson, P. Laurent, A. Kihn, M. Prevost, P. Servais, Impact of temperature on nitrification in biological activated carbon (BAC) filters used for drinking water treatment, Water Res. 35 (2001) 2923-2934.

[5] M.J. Kirisits, V.L. Snoeyink, H. Inan, J.C. Chee-Sanford, L. Raskin, J.C. Brown, Water quality factors affecting bromate reduction in biological active carbon filters, Water Res. 35 (2001) 891-900.

[6] C.H. Liang, P.C. Chiang, E.E. Chang, Systematic approach to quantify adsorption and biodegradation in biological activated carbon, Ozone Sci. Eng. 25 (2003) 351-361.

[7] D. Urfer, P.M. Huck, S.D.J. Booth, B.M. Coffey, Biological filtration for BOM and particle removal: a critical review, J. Am. Water Works Assoc. 89 (1997) 83-98.

[8] B.E. Rittmann, P.L. McCarty, Variable-order model of bacterial-film kinetics, J. Environ. Eng. (ASCE) 104 (1978) 889-900.

[9] B.E. Rittmann, P.L. McCarty, Substrate flux into biofilms of any thickness, J. Environ. Eng. (ASCE) 107 (1981) 831-849.

[10] H.T. Chang, B.E. Rittmann, Mathematical modeling of biofilm on activated carbon, Environ. Sci. Technol. 21 (1987) 273-280.

[11] P.M. Huck, S. Zhang, M.L. Price, BOM removal during biological treatment: a first-order model, J. Am. Water Works Assoc. 86 (1994) 61-71.

[12] A. Sakoda, J. Wang, M. Suzuki, Microbial activity in biological activated carbon bed by pulse responses, Water Sci. Technol. 34 (1996) 222-231.

[13] S. Zhang, P.M. Huck, Biological water treatment: a kinetic modeling approach, Water Res. 30 (1996) 1195-1207.

[14] G.M. Walker, L.R. Weatherley, A simplified predictive model for biologically activated carbon fixed beds, Process. Biochem. 32 (1997) 327-335.

[15] R.J. Abumaizar, E.H. Smith, W. Kocher, Analytical model of dual-media biofilter for removal of organic air pollutants, J. Environ. Eng. (ASCE) 123 (1997) 606-614.

[16] R.M. Hozalski, E.J. Bouwer, Non-steady-state simulation of BOM removal in drinking water biofilters: model development, Water Res. 35 (2001) 198-210.

[17] M.A. Carlson, K.M. Heffernan, C.C. Ziesemer, E.G. Snyder, Comparing two GAC for adsorption and biostabilization, J. Am. Water Works Assoc. 86 (1994) 91-102.

[18] E. Morgenroth, P.A. Wilderer, Influence of detachment mechanisms on competition in biofilms, Water Res. 34 (2000) 417-426.

[19] U. Telgmann, H. Horn, E. Morgenroth, Influence of growth history on sloughing and erosion from biofilms, Water Res. 38 (2004) 3671-3684.

[20] H. Horn, H. Reiff, E. Morgenroth, Simulation of growth and detachment in biofilm systems under defined hydrodynamic conditions, Biotechnol. Bioeng. 81 (2003) 607-617.

[21] C. Picioreanu, M.C.M. van Loosdrecht, J.J. Heijnen, Two-dimensional model of biofilm detachment caused by internal stress from liquid flow, Biotechnol. Bioeng. 72 (2001) 205-218.

[22] P.L. Bishop, T.C. Zhang, Y.C. Fu, Effects of biofilm structure, microbial distributions and mass transport on biodegradation processes, Water Sci. Technol. 31 (1995) 143-152.

[23] C.H. Liang, P.C. Chiang, E.E. Chang, Quantitative elucidation of the effect of EBCT on adsorption and biodegradation of biological activated carbon filters, J. Chin. Inst. Chem. Eng. 35 (2004) 1-9.

[24] D. Urfer, P.M. Huck, Measurement of biomass activity in drinking water biofilters using a respirometric method, Water Res. 35 (2001) 1469-1477. 